\title{
DIÁLOGO INCONCLUSO: OS CONCEITOS DE DIALOGISMO E POLIFONIA NA OBRA DE MIKHAIL BAKHTIN
}

\author{
Patrícia Marcuzzo*
}

\begin{abstract}
RESUMO: Dialogismo e polifonia são dois conceitos importantes na obra de Bakhtin acerca dos quais a crítica atual tem debatido com frequência (ver, por exemplo, os trabalhos de BRAIT, 1996, FARACO, 1996, BARROS, 2003 e BEZERRA, 2008). No entanto, muitas vezes, eles são utilizados como sinônimos em alguns trabalhos (BARROS, 2003, p. 5; EMERSON, 2003, p. 164). Portanto, o objetivo do presente artigo é discutir os conceitos de dialogismo e polifonia a partir de uma revisão da literatura, buscando definir e distinguir tais conceitos.
\end{abstract}

PALAVRAS-CHAVE: Dialogismo - Polifonia - Bakhtin

\begin{abstract}
Dialogism and polyphony are two important concepts in Bakhtin's work which have been often discussed by the critics (see, for example, BRAIT, 1996, FARACO, 1996, BARROS, 2003 and BEZERRA, 2008). However, they are frequently adopted as synonyms in some works (BARROS, 2003, p. 5; EMERSON, 2003, p. 164). Thus, the objective of the present paper is to discuss the concepts of dialogism and polyphony based on a review of literature, aiming at defining and distinguishing these concepts.
\end{abstract}

KEY-WORDS: Dialogism - Polyphony - Bakhtin

\section{CONTEXTUALIZAÇÃO}

Em Problemas da poética de Dostoiévski, Mikhail Mikhailovich Bakhtin faz uma observação original à obra do grande romancista russo. Contrapondo-se aos críticos anteriores do autor, Bakhtin destaca que Dostoiévski reencena, na obra literária, aquilo que seria a própria essência da linguagem: o dialogismo. Além disso, segundo Bakhtin, nenhum desses críticos teria sido capaz de enxergar, na obra do romancista, aquilo que realmente poderia distingui-la e que seria a sua grande contribuição para a arte do romance e para a teoria da linguagem: a polifonia, nome que Bakhtin toma emprestado da Música para nomear a inovação na relação autor/herói presente na obra de Dostoiévski (FARACO, 2008, p. 48).

Portanto, essas duas inovações - a palavra dialógica no interior de um desenho polifônico (dialogismo) e o herói plenivalente (polifonia) - constituem o núcleo teórico da obra Problemas da poética de Dostoiévski (EMERSON, 2003, p. 162) e se configuram em dois conceitos-chave importantes na obra de Bakhtin acerca dos quais a crítica atual tem debatido com frequência (ver os trabalhos de BRAIT, 1996; FARACO, 1996; BARROS, 2003; BEZERRA, 2008, para citar alguns exemplos).

\footnotetext{
* Mestre e doutoranda em Letras-Estudos Linguísticos/Universidade Federal de Santa Maria (UFSM), patimarcuzzo@yahoo.com.br. Agradeço a leitura dos pareceristas da revista Cadernos do IL.
} 
Tendo em vista que, muitas vezes, polifonia e dialogismo são utilizados como sinônimos, conforme destacam Barros (2003, p. 5) e Emerson (2003, p. 164), discuto, no presente artigo, esses dois conceitos a partir de uma revisão da literatura. O objetivo é tentar mostrar pontos de contato entre esses dois conceitos para, então, distingui-los. Este artigo está dividido em quatro seções, além desta Contextualização. Inicialmente, abordo o conceito de dialogismo e, em seguida, o conceito de polifonia. Posteriormente, busco distinguir esses dois conceitos. Por fim, apresento breves considerações finais à guisa de fechamento deste trabalho.

\section{BAKHTIN E O DIALOGISMO}

O conceito de dialogismo é fundamental para se compreender a obra de Bakhtin porque permeia a sua concepção de linguagem e, quem sabe, mais do que isso, sua concepção de mundo, de vida (BARROS, 2003, p. 2). No entanto, antes de conceituar dialogismo na obra de Bakhtin, é importante entender o conceito de discurso na obra do filósofo russo, tendo em vista que esses dois conceitos estão intrinsecamente relacionados. Para Bakhtin, discurso é

a língua em sua integridade concreta e viva e não a língua como objeto específico da linguística, obtido por meio de uma abstração absolutamente necessária de alguns aspectos da vida concreta do discurso. Mas são justamente esses aspectos, abstraídos pela linguística, os que têm importância primordial para nossos fins. (BAKHTIN, 2008, p. 207)

Nesse trecho, Bakhtin apresenta a sua concepção de discurso, ou seja, a "linguagem em ação" e também faz uma crítica a Saussure, o qual entendia a língua como um sistema de formas, estável e imutável, abstraído das relações sociais (BAKHTIN, 1986, p. 85). Para Bakhtin, a verdadeira substância da língua é constituída justamente nas relações sociais, via interação verbal, realizada por meio da enunciação ou das enunciações (ibid., p. 123). A partir disso, o discurso (a língua em sua integridade concreta e viva) não é individual porque se constrói entre, pelo menos, dois interlocutores que, por sua vez, são seres sociais; e se constrói como um "diálogo entre discursos", ou seja, mantém relações com outros discursos que o precederam (BARROS, 1996, p. 33). É aqui que entra o dialogismo, entendido como a condição do sentido do discurso (BARROS, 2003, p. 2).

No entanto, é importante ressaltar que o conceito de dialogismo em Bakhtin não está atrelado à ideia de um diálogo face a face entre interlocutores, mas sim entre discursos, já que "o interlocutor só existe enquanto discurso" (FIORIN, 2006, p. 166). Fiorin acrescenta também que por isso "todo enunciado possui uma dimensão dupla, pois revela duas posições: a sua e a do outro" (ibid., p. 170).

Além disso, é importante destacar que o termo diálogo/dialogismo é utilizado de três modos diferentes na obra de Bakhtin, conforme afirmam Morson e Emerson (2008), o que pode causar certa confusão para quem procura compreendê-los. Por isso, a seguir, destaco essas três diferentes acepções antes de definir dialogismo e monologismo.

O termo diálogo/dialogismo é utilizado em Bakhtin 
como uma descrição da linguagem que torna todos os enunciados, por definição, dialógicos; como termo para um tipo específico de enunciado, oposto a outros enunciados, monológicos; e como uma visão do mundo e da verdade (seu conceito global). (ibid., p. 506)

Embora o termo diálogo/dialogismo receba acepções diferentes na obra do filósofo russo, dependendo do contexto em que é empregado, este tem uma relação de unidade na medida em que engloba a ideia de Bakhtin sobre linguagem e, mais do que isso, homem e vida (BARROS, 1996, p. 26). O caráter dialógico é o fato unificador de todas as atividades linguageiras (FARACO, 1996, p. 122). Além disso, esse conceito define o ser humano, pois o outro é imprescindível para sua concepção: é impossível pensar no homem fora das relações que o ligam ao outro (ibid., p. 122). Assim, para Bakhtin, a alteridade é a condição da identidade: os outros constituem dialogicamente o eu que se transforma dialogicamente num outro de novos eus (ibid., p. 125), no sentido de que uma pessoa deve passar pela consciência do outro para se constituir (id., 2008, p. 43). No entanto, neste trabalho, procuro enfatizar a segunda acepção apontada por Morson e Emerson (2008) - as formas de discurso dialógicas e monológicas -, tendo em vista que esse é o viés do campo de estudos linguísticos.

À guisa de definição, o monologismo se refere a um discurso único, definitivo e uniforme. O monologismo não deixa revelar os outros discursos que permeiam a prática discursiva. Na análise de Bakhtin sobre os romances, aqueles considerados monológicos apresentam uma única voz, a do próprio autor do romance. No universo monológico, as personagens não têm mais nada a dizer, pois já disseram tudo, e o autor, de sua posição distanciada e com seu excedente de visão, já disse a última palavra por elas e por si (BEZERRA, 2008, p. 192). Desse modo, nas obras monológicas, o poder direto de significar pertence exclusivamente ao autor (MORSON; EMERSON, 2008, p. 255). Assim, essas obras

podem transmitir a posição do autor de várias maneiras. Às vezes uma dada personagem pode expressá-la; outras vezes a verdade do autor pode dispersar-se por uma variedade de personagens. Em algumas obras, ela pode não receber expressão direta ou explícita; não obstante, a verdade do autor permeia toda a estrutura da obra, que não pode ser compreendida sem ela (ibid., p. 254).

Já o dialogismo é explicado por Bakhtin a partir da análise dos romances de Dostoiévski. Nesses romances, não há o apagamento de vozes em detrimento da voz autoritária do autor. Como afirma Bakhtin:

\begin{abstract}
Assim, pois, nas obras de Dostoiévski não há um discurso definitivo, concluído, determinante de uma vez por todas. (...) A palavra do herói e a palavra sobre o herói são determinadas pela atitude dialógica aberta face a si mesmo e ao outro. (...) No mundo de Dostoiévski não há discurso sólido, morto, acabado, sem resposta, que já pronunciou sua última palavra (BAKHTIN, 2008, p. 291-292).
\end{abstract}

Desse modo, as obras do romancista russo são dialógicas, na medida em que resultam do embate de muitas vozes sociais (BARROS, 2003, p. 5-6). Conforme destaca Faraco (1996, p. 124), essas vozes são manifestações discursivas sempre relacionadas a um tipo de atividade humana e sempre axiologicamente orientadas apresentam uma atitude valorativa dos participantes do acontecimento a respeito do que 
ocorre em relação ao objeto do enunciado, em relação aos outros enunciados, em relação aos interlocutores (RODRIGUES, 2005, p. 161).

Bakhtin destaca que essas relações dialógicas entre discursos

\begin{abstract}
não são linguísticas no sentido rigoroso do termo. Podem ser situadas na metalinguística, subentendo-a como um estudo - ainda não-constituído em disciplinas particulares definidas - daqueles aspectos da vida do discurso que ultrapassam - de modo absolutamente legítimo - os limites da linguística. As pesquisas metalinguísticas, evidentemente, não podem ignorar a linguística e devem aplicar os seus resultados. A linguística e a metalinguística estudam um mesmo fenômeno concreto, muito complexo e multifacético - o discurso, mas estudam sob diferentes aspectos e diferentes ângulos de visão. Devem completar-se mutuamente e não fundir-se. (BAKHTIN, 2008, p. 207)
\end{abstract}

Para Bakhtin, as análises dialógicas não são linguísticas no sentido rigoroso do termo porque a Linguística se dedica ao estudo da "linguagem" propriamente dita, com sua lógica específica na sua generalidade, como algo que torna possível a comunicação dialógica (BAKHTIN, 2008, p. 209). De acordo com o filósofo russo, na língua vista como objeto da Linguística a partir da perspectiva saussuriana, não há e nem pode haver quaisquer relações dialógicas, pois elas são consideradas

impossíveis entre os elementos no sistema da língua (entre os morfemas, as palavras, as orações, etc.), entre os elementos da língua no texto e mesmo entre os elementos do "texto" e os textos no seu enfoque "rigorosamente linguístico”. (RODRIGUES, 2005, p. 156)

Para o estudo das relações dialógicas, Bakhtin propõe então a Metalinguística, uma nova ciência criada pelo filósofo para dar conta da análise dessas relações. No entanto, conforme afirma Brait (2006, p. 58), embora ofereça uma ótica diferenciada, Bakhtin não exclui a Linguística na análise dessas relações. Ao contrário, Bakhtin recomenda aplicar os seus resultados (ibid., p. 58). A Linguística se encarregaria de fazer uma análise interna, ou seja, da língua, enquanto a Metalinguística se encarregaria de fazer uma análise externa, já que as relações dialógicas são entendidas por Bakhtin como extralinguísticas. Conforme explica Brait (ibid., p. 58):

\begin{abstract}
O trabalho metodológico, analítico e interpretativo com textos/discursos se dá, como se pode observar nessa proposta de criação de uma nova disciplina, ou conjunto de disciplinas, herdando da linguística a possibilidade de esmiuçar campos semânticos, descrever e analisar micro e macro organizações sintáticas, reconhecer, recuperar e interpretar marcas e articulações enunciativas que caracterizam o(s) discurso(s) e indiciam sua heterogeneidade constitutiva assim como a dos sujeitos aí instalados. A partir do diálogo com o objeto de análise, chegar ao inusitado se sua forma de ser discursivamente, à sua maneira de participar ativamente de esferas de produção, circulação e recepção, encontrando sua identidade nas relações dialógicas estabelecidas com outros discursos, com outros sujeitos.
\end{abstract}

Desse modo, conforme afirma Faraco (1996, p. 121), Bakhtin é o primeiro pensador contemporâneo a tratar e analisar a linguagem sem a necessidade de divorciála da materialidade da vida social. Isso é possível a partir das concepções de Bakhtin acerca do discurso e, principalmente, do dialogismo. 
Na próxima seção, discuto o conceito de polifonia. Para tanto, tento recuperar o caminho analítico percorrido pelo filósofo russo, apresentando as análises por ele realizadas dos romances de Dostoiévski.

\section{BAKHTIN E A POLIFONIA}

A inovação na relação entre autor e herói, Bakhtin denominou, experimentalmente, de polifonia - que, segundo Faraco (2008, p. 48), é certamente um dos temas mais difíceis do seu pensamento. A ideia de polifonia foi tão radical para Bakhtin que foi responsável por causar uma verdadeira mudança de paradigma na história do romance (EMERSON, 2003, p. 161).

Para chegar ao conceito de polifonia, Bakhtin analisa desde a primeira obra de Dostoiévski - Gente Pobre - até seu último romance - Os Irmãos Karamazov. Bakthin destaca que, desde Gente Pobre, percebe-se a representação do discurso do outro na forma de sua antecipação no monólogo de um dos personagens (BAKHTIN, 2008, p. 235). Em O Duplo, obra que Bakhtin comenta depois de Gente Pobre, há um diálogo interior de um personagem cindido em três vozes dissonantes. Conforme analisa o filósofo russo:

Usando a nossa imagem, podemos dizer que isso ainda não é polifonia, mas também já não é homofonia. A mesma palavra, a mesma ideia e o mesmo fenômeno já são aplicados por três vozes e em cada uma soam de modo diferente. (ibid., p. 253)

No entanto, Bakhtin destaca que essas vozes ainda não teriam se tornado "plenamente autônomas, vozes reais, três consciências com plenos direitos" (ibid., p. 254).

Já em Memórias do Subsolo, a palavra do outro começa a tomar outra estatura. Ainda que a obra tenha sido composta na forma de uma confissão do personagem principal, em todo momento, percebe-se, segundo Bakhtin, a presença angustiante do outro. Assim, o discurso é eminentemente dialógico:

(...) todo o estilo da novela se encontra sob a influência fortíssima e tododeterminante da palavra do outro, que atua veladamente sobre o discurso de dentro para fora, como no início da novela, ou, enquanto réplica antecipada do outro, introduz-se-lhe diretamente no tecido (...). Na novela não há uma só palavra que se baste a si mesma e ao seu objeto, ou seja, nenhum discurso monológico. (ibid., p. 265)

O monólogo do "homem do subsolo" é sempre voltado para o outro. Por meio do uso da antecipação da réplica dos outros, essa personagem mantém sempre a última palavra para si, simulando uma autonomia em relação ao outro que, na verdade, ela nunca consegue atingir. Como afirma Bakhtin (ibid., p. 266), "graças a essa relação com a consciência do outro se obtém um original perpetuum mobile da polêmica do herói com o outro e consigo mesmo...". Nesse sentido, a obra poderia continuar indefinidamente.

O objetivo da confissão do "homem do subsolo" é libertar-se do poder exercido pelo outro sobre si mesmo, a fim de alcançar o caminho para si mesmo (ibid., p. 268). Contudo, no uso da evasiva, artifício empregado pelo herói para manter a possibilidade 
de mudança do sentido último de seu discurso, percebe-se, segundo Bakhtin, a contínua dependência do herói em relação ao olhar do outro (ibid., p. 268-269). O discurso do "homem do subsolo", em virtude dessa sua dependência em relação ao outro, é integralmente um "discurso-apelo", uma vez que, para ele, "falar é apelar para alguém" (ibid., p. 274). Como afirma Bakhtin:

\begin{abstract}
O momento de apelo é inerente a todo discurso em Dostoiévski, ao discurso da narração no mesmo grau que ao discurso do herói. No mundo de Dostoiévski não há, de um modo geral, nada de concreto, não há objetos, referentes, há apenas sujeitos. Por isso, (...) há apenas o discurso-apelo, o discurso que contata dialogicamente com outro discurso, o discurso sobre o discurso, voltado para o discurso. (ibid., p. 274)
\end{abstract}

Do mesmo modo que o "homem do subsolo", Raskólnikov, personagem principal da obra Crime e Castigo, de Dostoiévski, também realizaria um discursoapelo. No entanto, nos romances do escritor russo, segundo Bakhtin, percebe-se, à diferença das obras anteriores, uma dialogação interior mais viva e refinada (ibid., p. 275).

Como característica do discurso interior de Raskólnikov, cada personagem seria englobada por ele não como um caráter ou tipo, mas como símbolo de alguma diretriz ideológica. Assim, seu discurso interior se desenvolveria como uma espécie de drama filosófico (ibid., p. 276).

Uma vez que, nos romances de Dostoiévski, há várias vozes em conflito, surge como tarefa de suas personagens romanescas "encontrar sua voz e orientá-la entre outras vozes, combiná-la com umas, contrapô-la a outra ou separar a sua voz da outra à qual se funde imperceptivelmente" (ibid., p. 277). Isso é o que determinaria o discurso do herói nos romances dostoiévskianos.

Desse modo, Dostoiévski chega à polifonia. Para o filósofo russo, nas obras de Dostoiévski,

\begin{abstract}
a voz do herói sobre si mesmo e o mundo é tão plena como a palavra [...] do autor; não está subordinada à imagem objetificada do herói como uma de suas características mas tampouco serve de intérprete da voz do autor. Ela possui independência excepcional na estrutura da obra, é como se soasse ao lado da palavra do autor, coadunando-se de modo especial com ela e com as vozes plenivalentes de outros heróis. (BAKHTIN, 2008, p. 5)
\end{abstract}

A partir da inovação autor/herói, a polifonia pode ser entendida como "a multiplicidade de vozes equipolentes, as quais expressam diferentes pontos de vista acerca de um mesmo assunto" (ibid., p. 4 e 38-9). Elas são equipolentes na medida em que mantêm com as outras vozes do discurso uma relação de absoluta igualdade como participantes de um grande diálogo inconcluso (id., 2003, p. 348). Essas vozes representam uma multiplicidade de consciências e seus mundos que se combinam numa unidade de acontecimento (id., 2008, p. 5) e não são apenas objetos do discurso de autor, são também sujeitos de seus próprios discursos (BEZERRA, 2008, p. 195). Assim, a essência da polifonia consiste

no fato de que as vozes, aqui, permanecem independentes e, como tais, combinam-se numa unidade de ordem superior à homofonia. E se falarmos de vontade individual, então é precisamente na polifonia que ocorre a combinação de várias vontades individuais, realiza-se a saída de princípio 
para além dos limites de uma vontade. Poder-se-ia dizer assim: a vontade artística da polifonia é a vontade de combinação de muitas vontades, a vontade do acontecimento (BAKHTIN, 2008, p. 23).

Nas obras polifônicas, o autor continua presente, mas atua como

o regente do grande coro de vozes que participam do processo dialógico. Mas esse regente é dotado de um ativismo especial, rege vozes que ele cria ou recria, mas deixa que se manifestem com autonomia. (BEZERRA, 2005, p. 194)

A presença de uma multiplicidade de vozes, no romance e nos textos em geral, tem a função de marcar diferentes pontos de vista acerca de um determinado assunto. No entanto, Bakhtin não propõe uma metodologia de análise das estratégias de polifonia utilizadas nos textos, tendo em vista que esse não era seu objetivo. Mais do que isso, conforme afirma Faraco (2008, p. 49), a polifonia não recebeu um acabamento conceitual, de modo que "o termo vale hoje mais pela sedução derivada de livres associações do que como categoria coerente de um certo arcabouço teórico". Portanto, conforme destaca Barros (1996, p. 37), "cabe aos estudiosos do texto examinar as estratégias, os procedimentos, os recursos que fazem de um texto dialogicamente constituído por discursos monofônicos ou polifônicos".

De fato, alguns estudiosos da linguagem têm se dedicado aos estudos dos discursos monofônicos e polifônicos, dentre os quais se destacam os trabalhos de J. Authier-Revuz, D. Maingueneau e O. Ducrot. No entanto, para Barros (ibid., p. 38), foram sem dúvida os estudos de Ducrot que introduziram, de modo efetivo e sistemático, as reflexões de Bakhtin sobre dialogismo e polifonia nas reflexões linguísticas atuais.

$\mathrm{Na}$ próxima seção deste texto, tento distinguir dialogismo e polifonia, destacando pontos de contato entre esses dois conceitos para então distingui-los.

\section{DIALOGISMO VERSUS POLIFONIA}

Dialogia foi o termo que Bakhtin mais usou para descrever a vida do mundo da produção e das trocas simbólicas, composto por um universo de signos (RONCARI, 2003, p. X). O termo dialogismo se refere, conforme explorado ao longo desse trabalho, ao "princípio constitutivo da linguagem e de todo discurso", enquanto que a polifonia pode ser entendida como uma estratégia discursiva acionada na construção de um texto (BARROS, 2003, p. 5-6).

Nos textos polifônicos, as vozes se mostram; nos textos monofônicos, elas se ocultam sob a aparência de uma única voz (ibid., p. 6). Assim, o termo polifônico é empregado para caracterizar certo tipo de texto, aquele em que se deixam entrever muitas vozes, por oposição aos textos monofônicos, que escondem os diálogos que os constituem (ibid., p. 6). Para produzir um efeito de polifonia,

o autor projeta o discurso em primeira pessoa, isto é, o sujeito da enunciação atribui a palavra e o saber a um narrador, mas ao mesmo tempo em que faz essa delegação, o sujeito da enunciação, por meio de outra ou de outras vozes, desqualifica o narrador como sujeito do saber, mais precisamente, do 
saber interpretar. Não há, dessa forma, no discurso, uma voz “confiável” que possa interpretar e resolver a ambiguidade narrativa. (id.,1996, p. 40)

Portanto, os textos são dialógicos porque resultam do embate de muitas vozes sociais; podem, no entanto, produzir efeitos de polifonia, quando essas vozes ou algumas delas deixam-se escutar, ou de monofonia, quando o diálogo é mascarado, e uma voz, apenas, faz-se ouvir (id., 2003, p. 6).

\section{CONSIDERAÇÕES FINAIS}

Neste trabalho, tentei conceituar e distinguir dialogismo e polifonia, dois conceitos-chave na obra de Bakhtin e fundamentais para o campo de estudos da linguagem, os quais, muitas vezes, são utilizados como sinônimos. O dialogismo define as relações linguageiras, as práticas discursivas e, mais do que isso, a visão de mundo de Bakhtin. Já a polifonia se refere à multiplicidade de vozes em um texto, seja ele literário ou não. A polifonia pressupõe uma multiplicidade de mundos, ou seja, vários sistemas de referência, vozes plenivalentes e pontos de vista ideológicos acerca do mundo (BAKHTIN, 2008, p. 38-39).

Assim, de fato, esses dois conceitos são diferentes na obra de Bakhtin, conforme apontado ao longo deste texto. Dialogismo se refere ao princípio constitutivo da linguagem, enquanto a polifonia é uma estratégia discursiva, conforme destaca Barros (2003). O dialogismo é resultante de um embate de vozes, enquanto a polifonia é a menção a essas vozes em um texto. Assim, todo texto é, por essência, dialógico, mas nem todo texto é polifônico.

Pode-se apontar, pelo menos, duas razões para uma certa confusão em torno desses conceitos: 1) as três diferentes acepções que Bakhtin apresenta para o conceito de dialogismo e 2) as relações muito próximas entre os conceitos. Desse modo, cabe aos estudiosos da linguagem examinar os recursos e as estratégias que tornam um texto dialógico e/ou polifônico.

\section{REFERÊNCIAS}

BAKHTIN, Mikhail Mikhailovich. Marxismo e filosofia da linguagem: problemas fundamentais do método sociológico na ciência da linguagem. Tradução Michel Lahud e Yara Frateschi Vieira, com a colaboração de Lucia Teixeira Wisnik e Carlos Henrique D. Chagas Cruz. $3^{\text {a }}$ ed. São Paulo: Hucitec, 1986.

BAKHTIN, Mikhail Mikhailovich. Problemas da poética de Dostoiévski. Tradução Paulo Bezerra. $4^{\mathrm{a}}$ ed. Rio de Janeiro: Forense Universitária, 2008.

BARROS, Diana Luz Pessoa de. Contribuições de Bakhtin às teorias do texto e do discurso. In: FARACO, Carlos Alberto; TEZZA, Cristovão; CASTRO, Gilberto (Orgs.) Diálogos com Bakhtin. Curitiba: Editora da Universidade Federal do Paraná, 1996. p. 21-42.

BARROS, Diana Luz Pessoa de. Dialogismo, Polifonia e Enunciação. In: BARROS, Diana Luz Pessoa de.; FIORIN, José Luiz (Orgs.). Dialogismo, Polifonia, Intertextualidade. $2^{\mathrm{a}}$ ed. $1^{\mathrm{a}}$ reimpr. São Paulo: Editora da Universidade de São Paulo, 2003. p. $1-9$. 
BEZZERRA, Paulo. Polifonia. In: BRAIT, Beth (Org.). Bakhtin: conceitos-chave. $4^{\mathrm{a}}$ ed. São Paulo: Contexto, 2008. p. 191-200.

BRAIT, Beth. A natureza dialógica da linguagem: formas e graus de representação dessa dimensão constitutiva In: FARACO, Carlos Alberto; TEZZA, Cristovão; CASTRO, Gilberto (Orgs.). Diálogos com Bakhtin. Curitiba: Editora da Universidade Federal do Paraná, 1996. p. 69-92.

BRAIT, Beth. As vozes bakhtinianas e o diálogo inconcluso. In: BARROS, Diana Luz Pessoa de; FIORIN, José Luiz (Orgs.). Dialogismo, Polifonia, Intertextualidade. $2^{\text {a }}$ ed. $1^{\text {a }}$ reimpr. São Paulo: Editora da Universidade de São Paulo, 2003. p. 11-27.

BRAIT, Beth. Uma perspectiva dialógica de teoria, método e análise. Gragoatá Publicação do Programa de Pós-graduação em Letras da Universidade Federal Fluminense, Niterói, n. 20, p. 47-62, $1^{\circ}$ sem. 2006.

CROWLEY, Tony. Language and History: Theories and Texts. New York: Routledge, 1996.

EMERSON, Caryl. Polifonia, Dialogismo, Dostoievski. IN: Os cem primeiros anos de Mikhail Bakhtin. Tradução Pedro Jorgensen Jr. Rio de Janeiro: DIFEL, 2003. p. 161-200.

FARACO, Carlos Alberto. O dialogismo como chave de uma antropologia filosófica constitutiva In: FARACO, Carlos Alberto; TEZZA, Cristovão; CASTRO, Gilberto (Orgs.). Diálogos com Bakhtin. Curitiba: Editora da Universidade Federal do Paraná, 1996. p. 113-126.

FARACO, Carlos Alberto. Autor e autoria. In: BRAIT, Beth (Org.). Bakhtin: conceitoschave. $4^{\text {a }}$ ed. São Paulo: Contexto, 2008.

FIORIN, José Luiz. Interdiscursividade e intertextualidade. In: BRAITH, Beth (Org.). Bakhtin: outros conceitos-chave. São Paulo: Contexto, 2006. p. 161-193.

MORSON, Gary Saul; EMERSON, Caryl. Mikhail Bakhtin: criação de uma prosaística. Tradução Antonio de Pádua Danesi. São Paulo: Editora da Universidade de São Paulo, 2008.

RODRIGUES, Rosângela Hammes. Os gêneros do discurso na perspectiva dialógica da linguagem: a abordagem de Bakhtin. IN: MEURER, José Luiz; BONINI, Adair; MOTTA-ROTH, Désirée (Orgs.). Gêneros: teorias, métodos, debates. São Paulo: Parábola Editorial, 2005. p. 152-183.

RONCARI, Luiz. Prefácio. In: BARROS, Diana Luz Pessoa de; FIORIN, José Luiz (Orgs.). Dialogismo, Polifonia, Intertextualidade. $2^{\mathrm{a}}$ ed. $1^{\mathrm{a}}$ reimpr. São Paulo: Editora da Universidade de São Paulo, 2003. p. IX-XII. 